\title{
Response of growth, quality parameters and photosynthetic apparatus of endive plant to different culture media
}

\author{
Katarzyna Kowalczyk ${ }^{1 *}$, Janina Gajc-Wolska ${ }^{1}$,Monika Marcinkowska ${ }^{1}$, \\ Magdalena D. Cetner' ${ }^{2}$ Hazem M. Kalaji ${ }^{2}$ \\ ${ }^{1}$ Department of Vegetable and Medicinal Plants \\ ${ }^{2}$ Department of Plant Physiology \\ Faculty of Agriculture and Biology, Warsaw University of Life Sciences \\ Nowoursynowska 166, 02-787, Warszawa, Poland
}

\begin{abstract}
Endive (Cichorium endivia L.) is a leaf vegetable with high vitamin and nutritional values. Therefore, an increase of its cultivation in Poland and other European countries has been observed in recent years. The aim of this research was to study the effect of different growth media on the quality and photosynthetic efficiency of different endive cultivars. The experiment was conducted in controlled greenhouse conditions. Endive was grown in three independent NFT cultivation systems: a standard culture medium (control, A1), a culture medium concentrated three-fold (A2) and a medium concentrated five-fold (A3). Four cultivars were used: 'Kethel', 'Barundi', 'Galanti' and 'Perceval'. The plants were examined for the number and weight of fullygrown leaves and the weight of roots, dry matter content and chemical quality attributes of endive such as ascorbic acid (AA), total soluble solids (TSS), chlorophyll and proline. In addition, several physiological traits such as modulated chlorophyll $a$ fluorescence were measured.

Both three-fold and five-fold increases of ion concentration in the nutrient solution induced stress in the endive plants. Our results showed that the photosynthetic efficiency of the tested endive plants was affected by the cultivar factor and only the highest (five-fold) ion concentration in the nutrient solution. Growth under a medium of three-fold ion concentration did not affect the photosynthetic efficiency, despite observed changes in the growth and quality parameters of the endive plants. This study suggests that the type of fluorescence measurements used in this experiment (modulated) cannot be recommended as a sufficient bioindicator during endive production.
\end{abstract}

Key words: chlorophyll fluorescence, concentration of ions, nutrient film technique, nutrient solution, hydroponics

\section{INTRODUCTION}

Endive (Cichorium endivia L.) is a leaf vegetable with high vitamin and nutritional values. Sesquiterpene lactones present in the plant's leaves that are responsible for its bitter taste increase the appetite and stimulate the secretion of bile (Peters and Van Amerongen 1998). Endive is also a source of ascorbic acid, carotenoids and flavonoids, valued in dietetics for their antioxidant properties. Therefore, an increase of its cultivation in Poland and other European countries has been observed in recent years. In greenhouses, endive is cultivated either traditionally or by using soilless systems in

\footnotetext{
*Corresponding author.

Tel.: +48 2259322 38;

e-mail: katarzyna_kowalczyk@sggw.pl (K. Kowalczyk).
} 
the form of horticultural or hydroponic substrates. The use of hydroponics often results in an excessive increase in the concentration of ions in the growth medium. The content and concentration of minerals are crucial for plant growth and development parameters as well as its quality. A periodic elevation in the nutrient solution's concentration is one of the possible methods used to enhance the yield in hydroponics. Oh et al. (2010), among others, obtained a significant increase in the antioxidant capacity of lettuce by cultivating the plant under moderate environmental stress. An excessive ion concentration in the growing medium may act as a stress factor impeding the balance of plant growth (De Pascale and Barbieri 1995). Many previous studies have shown that the tolerance of plants to high concentrations of ions in the medium is subject to different factors, including climatic and growing conditions. The reaction of the plant to salt stress depends on the concentration and amount of salt ions, the current developmental phase of the plant, properties of the growing medium and the cultivation conditions offered (Sonneveld 1988, Maas 1990, Wissemeier and Zuhlke 2002).

The aim of the research was to study the effect of increased nutrient solution concentration on the growth, quality and photosynthetic efficiency of the endive plant.

\section{MATERIAL AND METHODS}

The experiment was conducted in a greenhouse at the Department of Vegetable and Medicinal Plants in the experimental centre of the Warsaw University of Life Sciences $\left(52^{\circ} \mathrm{N}, 21^{\circ} \mathrm{E}\right)$. Endive was grown in three independent NFT cultivation systems (Nutrient Film Technique equipped with flowing gutter cultivation in a closed circuit medium). Four endive cultivars obtained from Rijk Zwaan, three crispum leaf cultivars ('Galanti' $\mathrm{F}_{1}$, 'Perceval' $F_{1}$ and 'Barundi' $F_{1}$ ) and one latifolium leaf cultivar (escarole chicory) 'Kethel' $\mathrm{F}_{1}$ were taken into consideration. Four-week endive seedlings produced on rock wool cubes, measuring $40 \times 40$ $\times 70 \mathrm{~mm}$, were placed in openwork pots before being planted in growing gutters filled with the control nutrient solution (NFT cultivation system). The control (standard) solution (A1) was contained in $1 \mathrm{dm}^{3} 140 \mathrm{mg} \mathrm{N}$ in the form of ions $\mathrm{NO}_{3}$ and the following elements in mg: $\mathrm{P}-50, \mathrm{~K}-300, \mathrm{Mg}-40$, $\mathrm{Ca}-200, \mathrm{Fe}-2, \mathrm{Mn}-0.6, \mathrm{~B}-0.3, \mathrm{Cu}-0.15, \mathrm{Zn}$ -0.3 and $\mathrm{Mo}-0.05$; the $\mathrm{pH}$ of the standard nutrient solution was at the level of 6.7 and EC was 2.8 $\mathrm{dS} \mathrm{m}{ }^{-1}$. The plants were supplied with light for
10 hours a day by 600 watt high pressure sodium grow lights, producing energy of $500 \mu \mathrm{E} \mathrm{m}^{-2} \mathrm{~s}^{-1}$ above the plants. After four weeks of treating the endive plants with the control nutrient solution and two weeks before harvest, a portion of the plants were treated with a nutrient solution containing a higher ion concentration: a standard culture medium (control, A1), culture medium concentrated three-fold (A2) - $\mathrm{pH} 6.0$ and EC $6.5 \mathrm{dS} \mathrm{m}^{-1}$, and concentrated five-fold (A3) - pH 5.9 and EC 9.8 $\mathrm{dS} \cdot \mathrm{m}^{-1}$. Endive reaction to stress, caused by a higher concentration of ions in the medium, was studied two weeks after changing the type of nutrient solution. The investigation was conducted twice under controlled microclimate conditions. The experiment was established in a random design, with four replications and eight plants in each.

The plants were examined for the number and weight of fully-grown leaves and the weight of the roots. The dry matter content and chemical quality attributes of endive were also examined. Dry matter was determined by drying leaf samples in an oven at $105^{\circ} \mathrm{C}$ for 24 hours. The content of ascorbic acid (AA) was determined using Tillmans' method; the content of total soluble solids (TSS) was determined using a digital refractometer. The relative content of chlorophyll $\mathrm{a}+\mathrm{b}$ was measured in leaves using a Minolta SPAD-502 (Japan) apparatus. The content of proline was determined using the method described by Bates et al. (1973). An evaluation of the photosynthetic efficiency of the plants, based on chlorophyll fluorescence measurements, was conducted directly on leaves for each plant with three leaves of different ages: external leaf (old), middle leaf, fully developed, and inner leaf (the youngest one). The result for each plant was the average of the results from all of those leaves. Measurements were taken using a FMS-2 Field Portable Pulse Modulated Chlorophyll Fluorescence Monitoring System (Hansatech Instruments Ltd., King's Lynn, Norfolk, England). The following parameters were measured: Fs - steady state fluorescence yield, Fm' - light-adapted fluorescence maximum, ФPSII - quantum efficiency of photosystem II (PSII). ФPSII was calculated as ФPSII = $\left[\mathrm{Fm}^{\prime}-\mathrm{F}\right] /$ Fm' (Genty at al. 1989). This parameter measures the proportion of the light absorbed by PSII that is used in photochemistry. It provides the rate of linear electron transport and so indicates overall photosynthesis. Therefore, it can give a measure of the efficiency of photosystem II. 
Statistical analysis was performed using a twoway analysis of variance (ANOVA). A detailed comparison of means was performed by the Tukey test at the significance level of $p=0.05$.

\section{RESULTS AND DISCUSSION}

The nutrient solution used in the study in threeand five-folded concentrations induced stress in the studied cultivars of endive (Fig. 1, Tab. 1). According to Jaleel et al. (2007), a plant is considered to be under stress when the intensity of the affecting factor causes a significant negative impact on its life processes (developmental, physiological, or biochemical). Sometimes, however, the stress factor, especially when present in low levels, may have a beneficial effect on the plant (Shannon and Grieve 1999, Shannon at al. 2000). It is believed that symptoms such as 'tipburn' occur when the impact or persistence of stress exceeds the individual plant tolerance (Saure 1998). Nevertheless, endive grown for 14 days in the three-fold concentrated nutrient solution produced leaf rosettes with smaller fresh mass and fewer leaves than endive plants grown in the control nutrient solution (Tab. 1). Plants grown in the five-fold concentrated nutrient solution had the lowest mass and the smallest number of leaves compared either to the control plants or plants treated with the three-fold concentrated nutrient solution. The inhibition of growth in response to a high concentration of nutrient solution was observed in all of the tested cultivars.

The weight of the roots of the plants subjected to stress conditions increased, and in the combination with the five-fold concentrated nutrient solution, it was significantly higher than in the control, but this mainly concerned the 'Kethel' cultivar (Tab. 1). This could be a result of osmotic stress provoked by salt stress (Kalaji and Pietkiewicz 1993). Among other researchers, Eraslan et al. (2007) found a reduction in the yield of lettuce grown in a saline medium or a medium with a large amount of boron. The stimulatory effect of salt on root growth in lettuce and endive was observed by Tzortzakis (2009). However, Munns (2002) suggests that the root system is less sensitive to adverse conditions such as salinity as compared to the aboveground part of the plants. The plants grown on the three-fold concentrated nutrient solution were characterized by higher total soluble solids, relative chlorophyll content and proline content as compared to endive obtained from the control nutrient solution (Tab. 1, Fig. 1). However, the highest content of dry mass, total soluble solids, chlorophyll and proline was observed in the plants from the five-fold concentrated nutrient solution. There was no observed significant effect of the medium used on the content of ascorbic acid

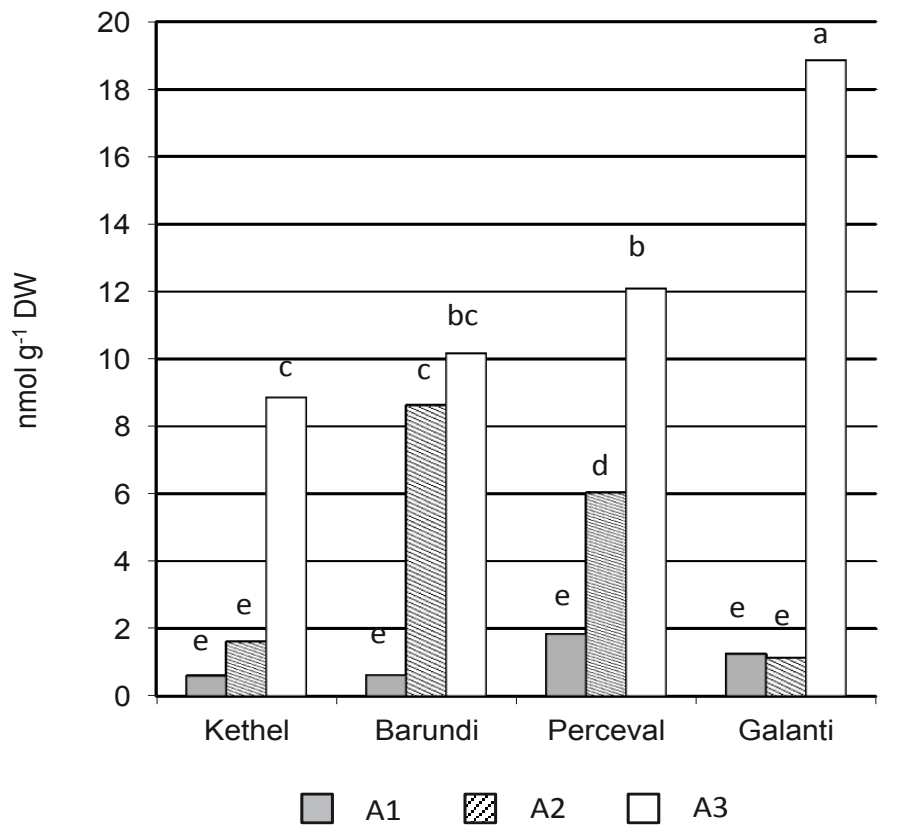

*Explanation: mean values for factors which do not differ according to Tukey's HSD test at $\mathrm{p}=0.05$ are marked with the same letters

Figure 1. Effect of nutrient concentration on proline content in endive leaves (average of two trials). Culture medium concentrated: A1-Control, A2 - three-fold, A3 - five-fold 
Table 1. Effect of nutrient concentration on the growth and quality parameters of endive (averages of two trials)

\begin{tabular}{|c|c|c|c|c|c|c|c|c|}
\hline Cultivar & $\begin{array}{l}\text { Concentration } \\
\text { of medium }\end{array}$ & $\begin{array}{l}\text { Weight } \\
\text { of plant } \\
(\mathrm{g})\end{array}$ & $\begin{array}{l}\text { Weight } \\
\text { of roots } \\
(\mathrm{g})\end{array}$ & $\begin{array}{c}\text { Number } \\
\text { of leaves } \\
\text { (No.) }\end{array}$ & $\begin{array}{c}\text { Dry } \\
\text { matter } \\
(\%)\end{array}$ & $\begin{array}{l}\text { TSS } \\
(\%)\end{array}$ & $\begin{array}{c}\mathrm{AA} \\
\left(\mathrm{mg} 100 \mathrm{~g}^{-1} \mathrm{FW}\right)\end{array}$ & $\begin{array}{l}\text { Chlorophyll } \\
\text { (SPAD) }\end{array}$ \\
\hline \multirow{3}{*}{ 'Kethel' } & Control & $420.1 \mathrm{a}^{*}$ & $60.3 \mathrm{bc}$ & $35.3 \mathrm{de}$ & $6.61 \mathrm{f}$ & $3.00 \mathrm{a}$ & $17.4 \mathrm{a}$ & $32.8 \mathrm{a}$ \\
\hline & 3-fold & $351.4 \mathrm{~b}$ & $110.1 \mathrm{~b}$ & $32.0 \mathrm{e}$ & $7.70 \mathrm{~cd}$ & $3.85 \mathrm{a}$ & $12.5 \mathrm{a}$ & $38.4 \mathrm{a}$ \\
\hline & 5-fold & $275.1 \mathrm{c}$ & $227.2 \mathrm{a}$ & $26.7 \mathrm{f}$ & $8.06 \mathrm{c}$ & $4.70 \mathrm{a}$ & $19.7 \mathrm{a}$ & $39.6 \mathrm{a}$ \\
\hline \multirow{3}{*}{ 'Barundi' } & Control & $207.0 \mathrm{~d}$ & $44.3 \mathrm{c}$ & $45.3 \mathrm{c}$ & $7.09 \mathrm{e}$ & $3.25 \mathrm{a}$ & $15.6 \mathrm{a}$ & $30.8 \mathrm{a}$ \\
\hline & 3-fold & $200.1 \mathrm{~d}$ & $56.2 \mathrm{bc}$ & $45.3 \mathrm{c}$ & $7.59 \mathrm{de}$ & $2.90 \mathrm{a}$ & $11.9 \mathrm{a}$ & $36.1 \mathrm{a}$ \\
\hline & 5-fold & $152.4 \mathrm{e}$ & 41.91 & $35.0 \mathrm{e}$ & $8.08 \mathrm{c}$ & $3.35 \mathrm{a}$ & $11.1 \mathrm{a}$ & $38.5 \mathrm{a}$ \\
\hline \multirow{3}{*}{ 'Perceval' } & Control & $295.8 \mathrm{c}$ & $62.9 \mathrm{bc}$ & $46.0 \mathrm{c}$ & $8.46 \mathrm{bc}$ & $3.10 \mathrm{a}$ & $15.8 \mathrm{a}$ & $35.2 \mathrm{a}$ \\
\hline & 3-fold & $210.1 \mathrm{~d}$ & $58.1 \mathrm{bc}$ & $47.3 \mathrm{c}$ & $7.64 \mathrm{~d}$ & $3.65 \mathrm{a}$ & $17.8 \mathrm{a}$ & $36.8 \mathrm{a}$ \\
\hline & 5-fold & $222.7 \mathrm{~d}$ & $86.6 \mathrm{bc}$ & $40.0 \mathrm{~d}$ & $9.46 \mathrm{a}$ & $5.15 \mathrm{a}$ & $11.6 \mathrm{a}$ & $38.9 \mathrm{a}$ \\
\hline \multirow{3}{*}{ 'Galanti' } & Control & $322.3 \mathrm{bc}$ & $69.9 \mathrm{bc}$ & $58.0 \mathrm{a}$ & $7.00 \mathrm{ef}$ & $3.15 \mathrm{a}$ & $15.5 \mathrm{a}$ & $32.7 \mathrm{a}$ \\
\hline & 3 -fold & $279.2 \mathrm{c}$ & $97.4 \mathrm{bc}$ & $46.0 \mathrm{c}$ & $8.79 \mathrm{~b}$ & $3.45 \mathrm{a}$ & $11.7 \mathrm{a}$ & $34.9 \mathrm{a}$ \\
\hline & 5-fold & $209.1 \mathrm{~d}$ & $76.7 \mathrm{bc}$ & $52.7 \mathrm{~b}$ & $8.63 \mathrm{~b}$ & $3.80 \mathrm{a}$ & $19.3 \mathrm{a}$ & $38.3 \mathrm{a}$ \\
\hline \multirow{3}{*}{ Mean } & Control & $311.3 \mathrm{a}$ & $59.3 \mathrm{~b}$ & $46.1 \mathrm{a}$ & $7.3 \mathrm{~b}$ & $3.1 \mathrm{c}$ & $16.1 \mathrm{a}$ & $32.9 \mathrm{c}$ \\
\hline & 3-fold & $260.2 \mathrm{~b}$ & $80.4 \mathrm{ab}$ & $42.7 \mathrm{~b}$ & $7.9 \mathrm{ab}$ & $3.6 \mathrm{~b}$ & $13.5 \mathrm{a}$ & $36.5 \mathrm{~b}$ \\
\hline & 5-fold & $214.8 \mathrm{c}$ & $109.5 \mathrm{a}$ & $38.6 \mathrm{c}$ & $8.6 \mathrm{a}$ & $4.5 \mathrm{a}$ & $15.4 \mathrm{a}$ & $38.8 \mathrm{a}$ \\
\hline
\end{tabular}

*Explanation: mean values for factors which do not differ according to Tukey's HSD test at $\mathrm{p}<0.05$ are marked with the same letters

in the endive leaves (Tab. 1). Although responses of the studied cultivars to stress conditions were similar, some differences were observed when comparing the values of particular parameters between cultivars. Eraslan et al. (2007) observed a decrease in the dry matter content of lettuce grown in saline medium $\mathrm{NaCl}$ and $\mathrm{NaCl}+$ Boron (B). However, the same authors have reported that a toxic concentration of nutrient solution in the medium B did not cause any significant changes in the lettuce's dry matter content. Many authors have reported that salinity affects the content of chlorophyll $\mathrm{a}$ and $\mathrm{b}$ in plants' leaves (Hawrylak 2007, Stoeva and Kaymakanova 2008). The applied three- and five-fold concentration of the medium seemed to increase the amount of chlorophyll in the leaves of endive. However, this result is obtained due to the use of chlorophyll content meters, which are based on optical measurements and does not consider the changes in leaf anatomy under stress conditions, e.g. changes in Specific Leaf Area (SLA), which is defined as the ratio of leaf area to dry mass (Kalaji et al 2014). The substance that plays a very important role in plant response to stress is proline (Claussen 2005, Szabados and Savouré 2009). The stress level was the strongest for endive in the five-fold concentrated medium when all the cultivars contained much more proline than the control plants (Fig. 1). Ascorbic acid, like proline, is important for osmotic adjustment functions, which in turn protect the plant enzymes and membranes from oxidative stress (Eraslan et al. 2007). In the case of media used, there was no accumulation of ascorbic acid in endive plants. Oh et al. (2009) observed an increase in ascorbic acid content in lettuce subjected to moderate and short-term environmental stress conditions, such as higher and lower temperature and intensified light,

Table 2. The actual photosystem II (PSII) efficiency (ФPSII) in dependence on nutrient solution concentration and cultivar of endive in hydroponic cultivation (averages of two trials)

\begin{tabular}{lccccc}
\hline \multirow{2}{*}{$\begin{array}{l}\text { Culture medium } \\
\text { concentration }\end{array}$} & \multicolumn{3}{c}{ Cultivar } & \multirow{2}{*}{ Mean } \\
\cline { 2 - 4 } Control & 0.790 & 0.751 & 0.756 & 'Galanti' & 0.760 \\
3-fold (A2) & 0.771 & 0.731 & 0.763 & 0.748 & 0.754 \\
5-fold (A3) & 0.767 & 0.739 & 0.752 & 0.740 & 0.749 \\
\hline Mean & 0.776 & 0.740 & 0.757 & 0.749 & \\
\hline
\end{tabular}

$\mathrm{LSD}_{0.05}$ for medium concentration $=0.01$; cultivar $=0.01$; medium concentration $\times$ cultivar $=$ n.s. 
while Stamatakis et al. (2003) reported no effect of $\mathrm{NaCl}$ salinity caused by the ascorbic acid content in tomato fruit.

The results of chlorophyll fluorescence measurements showed that the quantum efficiency of PSII (ФPSII) was affected by the concentration of ions in the culture medium and the endive cultivar (Tab. 2). A significant difference in the quantum efficiency of PSII (ФPSII) was found for five-fold concentrated nutrient solution compared to the control, but there was no significant difference for lower three-fold concentrated nutrient solution. The quantum efficiency of PSII (ФPSII) of 'Kethel' $\mathrm{F}_{1}$ (mean value of 0.776 r. u.) significantly differed from the quantum efficiency of PSII of the three other tested cultivars ('Barundi' $F_{1}$, 'Perceval' $F_{1}$ and 'Galanti' $F_{1}$ ), which are a crispum leaf type of endive. The reason could be differences in the morphology of the leaves of these endive cultivars. This suggests that the type of chlorophyll fluorescence used in this experiment (modulated fluorescence) could not reveal the effect of lower ion concentration in the growth medium (which, however, had the effect of abiotic stress) on the photosynthetic efficiency of the tested plants. In this case, another kind of chlorophyll fluorescence measurement such as prompt and delayed fluorescence could help to explore the changes in ФPSII functioning and efficiency (Kalaji et al. 2014).

\section{CONCLUSIONS}

1. Both three-fold and five-fold increases of ion concentration in the nutrient solution (growth medium) induced stress in the endive plants. This was expressed by a decreased yield and higher accumulation of dry matter, chlorophyll (SPAD), TSS and proline.

2. The five-fold concentrated solution's effect was stronger and more negative than the three-fold ion concentration's. The inhibition of growth in response to a high concentration of nutrient solution was observed in all of the tested cultivars.

3. Many changes were observed in the quantum efficiency of PSII of plants grown under five-fold ion concentrations, but not in the case of threefold ion concentrations.

\section{FUNDING}

The presented research was carried out thanks to statutory funds of the Warsaw University of Life Sciences.

\section{AUTHOR CONTRIBUTIONS}

K.K. designed the experiments and performed the statistical analysis, interpreted the data and wrote the paper; M.M. performed analytical measurements; M.D.C. conducted the observations. J.G-W. and H.M.K. interpreted the results equally.

\section{CONFLICT OF INTEREST}

Authors declare no conflict of interest.

\section{REFERENCES}

Bates L.S., Waldren R.P., Teare J.D., 1973. Rapid determination of free proline for water stress studies. Plant Soil 39: 205-207.

Claussen W., 2005. Proline as a measure of stress in tomato plants. Plant Sci. 168: 241-248.

De Pascale S., Barbieri G., 1995. Effects of soil salinity from long-term irrigation with saline-sodic water on yield and quality of winter vegetable crops. Sci. Hort. 64: 145-157.

Eraslan F., Inal A., Savasturk O., Gunes A., 2007. Changes in antioxidative system and membrane damage of lettuce in response to salinity and boron toxicity. Sci. Hort. 114: 5-10.

Genty B., Briantais J.M., Baker N.R., 1989. "The relationship between the quantum yield of photosynthetic electron transport and quenching of chlorophyll fluorescence". Biochem. Biophys. Acta 990: 87-92.

Hawrylak B., 2007. Fizjologiczna reakcja ogórka na stres zasolenia w obecności selenu. Roczniki AR w Poznaniu CCCLXXXIII(41): 483-486.

Jaleel C.A., Gopi R., Manivannan P., Panneerselvam R., 2007. Antioxidative potentials as a protective mechanism in Catharanthus roseus (L.) G. Don. plants under salinity stress. Turkish J. Bot. 31: 245251.

Kalaji M.H., Pietkiewcz S., 1993. Salinity effects on plant growth and other physiological processes. Acta Physiol. Plant. 15: 89-124.

Kalaji M.H., Schansker G., Ladle R.J., Goltsev V., Bosa K., Allakhverdiev S.I., Brestic M., Bussotti F. et al., 2014. Frequently Asked Questions about in vivo chlorophyll fluorescence: practical issues. Photosynthesis Res. 122: 121-158.

MaAs E., 1990. Crop salt tolerance. Asce, New York, Ny: 262-304.

Munns R., 2002. Comparative physiology of salt and water stress. Plant Cell Environ. 25: 239-250.

Oh M., Carey E.E., Rajashekar C., 2010. Regulated water deficits improve phytochemical concentration in lettuce. J. Amer. Soc. Hort. Sci. 135(3): 223-229.

Peters A.M., Van Amerongen A., 1998. Relationship between levels of sesquiterpene lactones in chicory and sensory evaluation. J. Amer. Soc. Hort. Sci. 123: 326-329. 
SAURE M.C., 1998. Review causes of the tipburn disorder in leaves of vegetables. Sci. Hort. 76: 131-147.

Shannon M.C., Grieve C.M., 1999. Tolerance of vegetable crops to salinity. Sci. Hort. 78: 5-38.

Shannon M.C., Grieve C.M., Lesch S.M., Draper J.H., 2000. Analysis of salt tolerance in nine leafy vegetables irrigated with saline drainage water. J. Amer. Soc. Hort. Sci. 125(5): 658-664.

Sonneveld C., 1988. The salt tolerance of greenhouse crops. Neth. J. Agr. Sci. 36: 63-73.

Stamatakis A., Papadantonakis N., Savvas D., Lydakis -Simantiris N., Kefalas P., 2003. Effects of silicon and salinity on fruit yield and quality of tomato grown hydroponically. Acta Hort. 609: 141-147.
Stoeva N., Kaymakanova M., 2008. Effect of salt stress on the growth and photosynthesis rate of bean plants (Phaseolus vulgaris L.). JCEA 9(3): 385-392.

Szabados L., Savouré A., 2009. Proline: a multifunctional amino acid. Trends Plant Sci. 15(2): 89-97.

Tzortzakis N.G., 2009. Influence of $\mathrm{NaCl}$ and calcium nitrate on lettuce and endive growth using nutrient film technique. Intl. J. Veg. Sci. 15: 1-13.

Wissemeier A.H., Zuhlke G., 2002. Relation between climatic variables, growth and the incidence of tipburn in field-grown lettuce as evaluated by simple, partial and multiple regression analysis. Sci. Hort. 93: 193-204.

Received July 13, 2015; accepted January 4, 2016 